\title{
IMPLEMENTATION OF CHOOSING WISELY CAMPAIGN IN HEALTH COURSES IN BRAZIL - DESCRIPTION OF THE FIRST STEPS
}

\author{
Marta Silva Menezes*, Marilia Menezes Gusmão**, Ana Marice Teixeira Ladeia*, Carolina Vila \\ Nova Aguiar***, Cristiane Magali Freitas dos Santos****, Luis Cláudio Lemos Correia*
}

\author{
Corresponding author: Marta Silva Menezes - martamenezes@bahiana.edu.br \\ *MD, PhD, professor at BAHIANA - School of Medicine and Public Health \\ **MD, MSc, graduation student at BAHIANA - School of Medicine and Public Health \\ ***LPsy, PhD, professor at BAHIANA - School of Medicine and Public Health \\ ****NP, MSc, PhD candidate and professor at BAHIANA - School of Medicine and Public Health
}

\section{A B S T R A C T}

Introduction: Popular medical decisions regarding testing or treatment are often ineffective or even harmful. Seeking an awareness of healthcare professionals and patients in this regard, it was created the international campaign "Choosing Wisely", whose strategy is based on creating lists containing situations that are frequent but of low value to patients. Objective: To describe the initial process of implementing Choosing Wisely Campaign in EBMSP. Material and methods: Descriptive study based on observational reports. Results: It was made a presentation to which the healthcare undergraduation courses coordinators of EBMSP were invited, followed by research group formation. The medical course list was written using an expert panel and it was sent to students and to the medical professors of the school. The partial results were presented in events of medical education and a Choosing Wisely meeting in Brazil. A student-aimed questionnaire to evaluate perceptions on cost-conscious attitudes and role-modeling behavior is currently being validated. Conclusion: It is noticeable the high interest of students and teachers on the campaign. Additionally, the development of a research activity helped systematization and organization of the actions and fast evolution of the research team.

Keywords: Economics, Education, Medical, Undergraduate 


\section{INTRODUCTION}

Popular medical decisions regarding testing or treatment are often ineffective or even harmful. Seeking an awareness of healthcare professionals and patients in this regard, it was created the international campaign "Choosing Wisely"'.

Its initial awareness-raising strategy is based on creating lists, containing situations in each specialty area in healthcare, which should be avoided or reconsidered, and subsequently disclosed to the community. The involvement of actions focused on undergraduate education is provided in the original campaign, however there are few medical schools that have applied this methodology so far ${ }^{2}$.

\section{OBJECTIVE}

To describe the initial "Choosing Wisely" campaign deployment proccess in BAHIANA-School of Medicine and Publich Health (Escola Bahiana de Medicina e Saúde Pública - EBMSP in Brazilian Portuguese).

\section{MATERIAL AND METHODS}

This is descriptive study, based on researchers" observations and records of meeting reports of the initial steps required to implementation of the Choosing Wisely campaign at BAHIANA, featuring the undergraduation courses in medicine, nursing, dentistry, psychology, physiotherapy, biomedicine and physical education.

\section{RESULTS AND DISCUSSION}

Initially, it was made a first contact with all courses coordinators. Although all have shown interest in participating in the campaign, four courses (medicine, nursing, dentistry and psychology) decided to join at that moment. After analysis of the applicability of the strategy of creating lists to the psychology course, it was concluded that it would be complex to perform it in that context. For this reason, it was determined that the psychology course participation would be in collaboration and support to other courses.

To ensure the systematization and analysis of the various stages of the implementation of the campaign and its sustainability, it was established a research group on the subject registered at National Council for Scientific and Technological Development (CNPq), the project was submitted to the Ethics and Research Committee and undergraduate and graduate students were involved.

It was established a schedule, with planned regular meetings with record of decisions on reports to be shared with all participants of the research group. Basic principles for the campaign were agreed upon for each course.

Everyone involved would follow the campaign purposes, with adjustments whenever necessary. As a general rule it was established that each course would build their own lists of recommendations. The conception of the list should be based on the competencies for each professional category, it would have to be applied to students in practical training, and questioning of the performance of other professional areas would not be accepted.

Medical school's planning was already on a later stage when the other courses joined the campaign. The process of building the list of propositions for the medical course had already been started. Considering the extent of the issues involved, the researchers decided to split the content in multiple topics, using as criteria the main general areas: Internal Medicine, Surgery, Pediatrics, Gynecology and Obstetrics. Internal Medicine was the area of choice for the initial project and criteria and strategies were determined for the construction of the expert panel. Subsequently, the nursing school also started the process of building their list of propositions.

After defining criteria and strategies for building the list of propositions, it was noticed the need for greater deepening and knowledge about the topic with an 
extensive literature review on the use of Choosing Wisely in other medical schools. On the scarcity of the theme, the research topic was expanded on the teaching of cost-conscious topics in medical schools, and the writing of a review article was proposed. Two types of review articles were considered for the methodology, a scoping review ${ }^{3,4}$ and a realistic systematic review ${ }^{5}$.

Another high priority aspect that was considered was to identify the measuring scale that allows evaluating the perception of cost-conscious attitudes and role-modeling behaviors.

An American study applied a questionnaire of perception of cost-consciousness attitudes and rolemodeling behavior to medical students on several medical school in the United States (US) ${ }^{6}$, and we decided to use this same questionnaire to our medical students at BAHIANA. Authorization was granted for translation and validation of this scale to Portuguese and to the Brazilian context by the author of that study, and validation steps are based on a guideline on validation, translation and adaptation of scales ${ }^{7}$.
At the moment the following steps were already carried out: translation, back translation, translation validation by native English speaking person, comparison of the back translated with the original English version, and semantic validation with medical students. Currently the scale is being tested with a larger number of students, so it will be possible to accomplish the completion of the validation process with psychometric analysis of the answers.

After the construction of the list of propositions, it was emailed to the students and professors of the course of BAHIANA medicine. Open-ended questions about participants' impressions of the campaign and the topic were also included in the online form. Partial results were presented in the Brazilian Congress of Medical Education held in Brasilia, DF, Brazil, between the 12th and 15th of October 2016, at the Choosing Wisely Symposium at BAHIANA on October 14th, and at the first Choosing Wisely Brazilian Meeting held in Curitiba, Paraná, Brazilon October 20th, 2016.

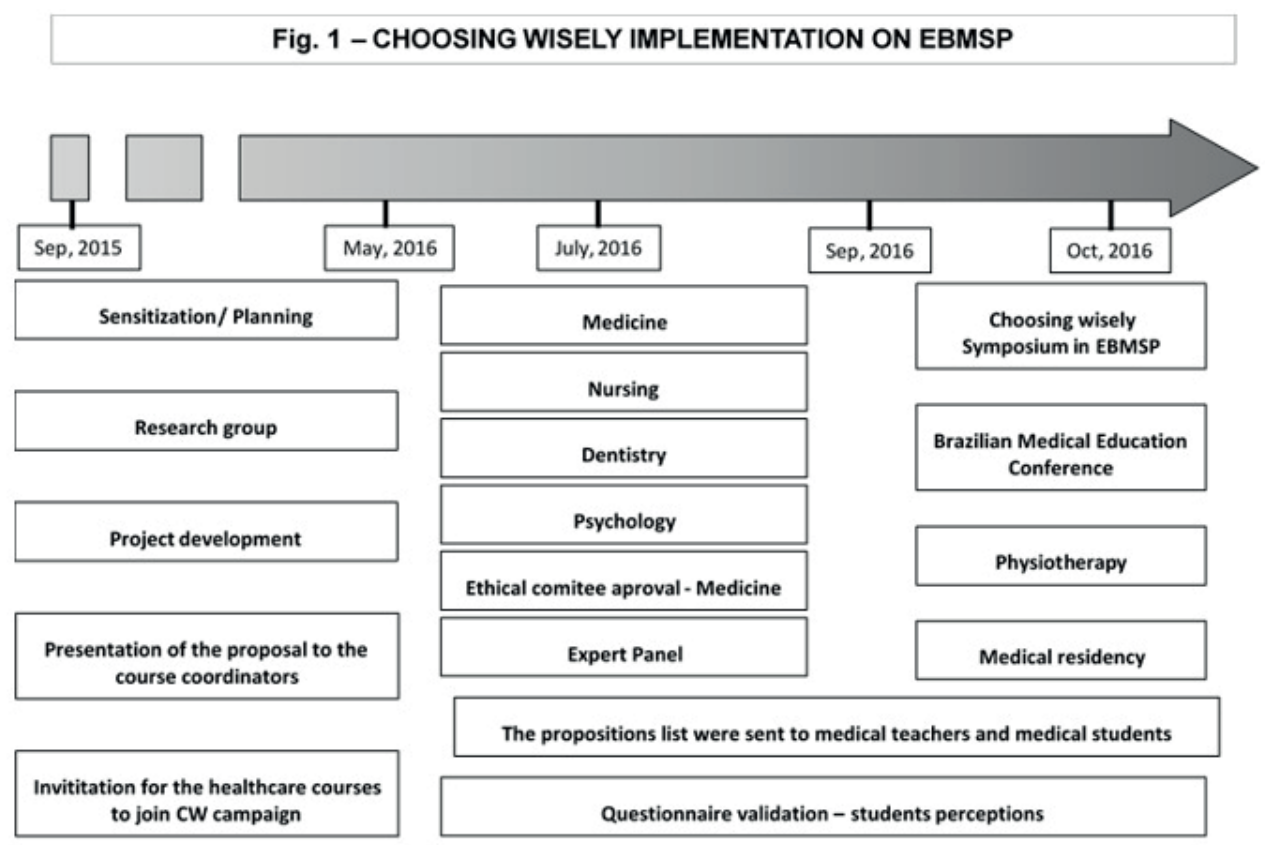

Figure 1. The various steps followed by the deployment and research group to date. Source: timetable created by the authors themselves

More recently, the physiotherapy course was incorporated into the project, as well as other areas of medicine and projects involving the residency and local medical specialties societies. Educational interventions are being planned to incorporate cost-consciousness into the courses, so it can be sustainable over the time. 


\section{CONCLUSIONS}

It is noticeable the high interest of professors and students in the campaign when sensitized about that theme. The recognition as a research activity provided systematization and organization of activities and a rapid evolution of the group. adaptation of self-report measures. Spine. 2000;25(24):3186-3191

\section{REFERENCES}

1. Cassel CK. Providing high-value, cost-conscious care. Ann Intern Med. 2011 ; 155(1 2):857-858. doi: 10.7326/0003-4819-155-12-20111220000014

2. Levinson W, Kallewaard M, Bhatia RS, Wolfson D, Shortt S, Kerr EA. "Choosing Wisely": a growing international campaign. BMJ Qual Saf. 1 de fevereiro de 2015;24(2):167-74. doi:10.1136/ bmiqs-2014-003821

3. Peters MD, Godfrey CM, Khalil H, Mclnerney $P$, Parker D, Soares CB. Guidance for conducting systematic scoping reviews. Int J Evid Based Healthc. 2015;13(3):141-6. doi: 10.1097/ XEB. 0000000000000050

4. Arksey H, O'Malley L. Scoping studies: towards a methodological framework. Int J Soc Res Methodol. 2005;8(1):19-32

5. Wong G, Greenhalgh T, Westhorp G, Buckingham J, Pawson R. RAMESES publication standards: realist syntheses. BMC Med. 2013;11:21. doi: 10.1186/1741-7015-11-21

6. Leep Hunderfund AN, Dyrbye LN, Starr SR, Mandrekar J, Naessens JM, Tilburt JC et al. Role Modeling and Regional Health Care Intensity: U.S. Medical Student Attitudes Toward and Experiences With Cost-Conscious Care. Acad Med J Assoc Am Med Coll. 2016;1 -9. doi: 10.1097/ ACM.0000000000001223

7. Beaton DE, Bombardier C, Guillemin F, Ferraz $M B$. Guidelines for the process of cross-cultural 